\title{
Evaluation of aerosol mixing state classes in the GISS modelE-MATRIX climate model using single-particle mass spectrometry measurements
}

\author{
Susanne E. Bauer, ${ }^{1}$ Andrew Ault, ${ }^{2,3}$ and Kimberly A. Prather ${ }^{2,4}$ \\ Received 15 February 2013; revised 1 August 2013; accepted 2 August 2013; published 5 September 2013.
}

[1] Aerosol particles in the atmosphere are composed of multiple chemical species. The aerosol mixing state, which describes how chemical species are mixed at the single-particle level, provides critical information on microphysical characteristics that determine the interaction of aerosols with the climate system. The evaluation of mixing state has become the next challenge. This study uses aerosol time-of-flight mass spectrometry (ATOFMS) data and compares the results to those of the Goddard Institute for Space Studies modelE-MATRIX (Multiconfiguration Aerosol TRacker of mIXing state) model, a global climate model that includes a detailed aerosol microphysical scheme. We use data from field campaigns that examine a variety of air mass regimens (urban, rural, and maritime). At all locations, polluted areas in California (Riverside, La Jolla, and Long Beach), a remote location in the Sierra Nevada Mountains (Sugar Pine) and observations from Jeju (South Korea), the majority of aerosol species are internally mixed. Coarse aerosol particles, those above $1 \mu \mathrm{m}$, are typically aged, such as coated dust or reacted sea-salt particles. Particles below $1 \mu \mathrm{m}$ contain large fractions of organic material, internally mixed with sulfate and black carbon, and few external mixtures. We conclude that observations taken over multiple weeks characterize typical air mass types at a given location well; however, due to the instrumentation, we could not evaluate mass budgets. These results represent the first detailed comparison of single-particle mixing states in a global climate model with real-time single-particle mass spectrometry data, an important step in improving the representation of mixing state in global climate models.

Citation: Bauer, S. E., A. Ault, and K. A. Prather (2013), Evaluation of aerosol mixing state classes in the GISS modelE-MATRIX climate model using single-particle mass spectrometry measurements, J. Geophys. Res. Atmos., 118, 9834-9844, doi:10.1002/jgrd.50700.

\section{Introduction}

[2] Atmospheric particles are rarely observed to be composed of a single chemical species [Whiteaker et al., 2002], yet still the scientific community [IPCC, 2007] discusses the fate of sulfate aerosols and dust aerosols, among others, as though they exist independently. This terminology is most likely influenced by the way we have historically observed and modeled aerosol particles. The first measurements used filter-based techniques to record the mass of a chemical species [Malm et al., 2011], while most

\footnotetext{
${ }^{1}$ Center for Climate Systems Research, The Earth Institute, Columbia University, New York, New York, USA.

${ }^{2}$ NASA Goddard Institute for Space Studies, New York, New York, USA.

${ }^{3}$ Now at Department of Chemistry, University of Iowa, Iowa City, Iowa, USA.

${ }^{4}$ Scripps Institution of Oceanography, University of California, San Diego, La Jolla, California, USA.

Corresponding author: S. E. Bauer, Center for Climate Systems Research, The Earth Institute, Columbia University, Broadway 2880, New York 10025, NY, USA. (Susanne.Bauer@Columbia.edu)

C2013. American Geophysical Union. All Rights Reserved. 2169-897X/13/10.1002/jgrd.50700
}

models have simulated separate aerosol life cycles for each chemical species.

[3] Details on the aerosol mixing state, such as the chemical components, water content, size, and shape (homogeneous mixed, core shell, etc.) of each particle, are of great importance for determining aerosol climate impacts. For example, a coated black carbon particle absorbs more radiation than its uncoated counterpart [Jacobson, 2006; Adachi et al., 2010], while a coated dust surface [Bauer et al., 2007] accelerates its wet removal and coagulated sulfate-organic carbon particles provide number concentrations for cloud condensation nucleus $(\mathrm{CCN})$ activation different from those counted separately [Bauer et al., 2010]. Given the impacts that changes in mixing state can have on the climate properties of aerosol distribution, it is necessary to accurately model their properties with enough complexity to capture these processes.

[4] To date, most measurements on the global scale are from space observations with remote sensing instruments (advanced very high resolution radiometer, Stratospheric Aerosol and Gas Experiment (SAGE), Total Ozone Mapping Spectrometer, Moderate Resolution Imaging Spectroradiometer, Multiangle Imaging Spectroradiometer, Ozone Monitoring Instrument, and Cloud-Aerosol Lidar and Infrared Pathfinder Satellite Observations (CALIOP)) on various satellite 
platforms. This has led to a valuable source of global aerosol maps that measure aerosol optical depth (AOD), absorption AOD, and aerosol height, as well as additional aerosol quantities describing the total aerosol loading. Other longterm ground observations, such as the Interagency Monitoring of Protected Visual Environments network in the United States and the European Monitoring and Evaluation Programme in the European Union, monitor time series of particle size and chemical mass loads. However, these remote and long-term measurements evaluate bulk aerosol distributions and, as the studies above have shown, knowledge of single-particle mixing state is necessary to evaluate aerosol impacts on climate. To investigate these processes, coordinated field campaigns provide in situ measurements over a shorter period of weeks to months and space with increasingly complex aerosol instrumentation. Aerosol mass measurements, optics (Sun photometer, SP2), hygroscopicity, size distributions, differential mobility particle sizer (DMPS), scanning mobility particle sizer (SMPS), and chemically resolved mass distributions (mass spectrometry such as AMS) have all provided insight into the complexity of aerosol particles on a bulk or average level. Single-particle measurements go a step further and allow for mixing state to be evaluated for individual particles. In particular, online techniques such as particle analysis by laser mass spectrometry (PALMS) [Murphy et al., 1998], SPLAT [Zelenyuk et al., 2009], RSMS [Carson et al., 1995], and aerosol time-of-flight mass spectrometry (ATOFMS) [Gard et al., 1997] allow observation of the chemical composition of single particles with high statistics, which finally allows us to study the details of the mixing state of aerosol particles.

[5] The first climate models that actively included aerosols contained the aerosol cycle by chemical species, beginning with the sulfur cycle [Schult et al., 1997] and then implementing additional chemical species (e.g., black carbon [Koch, 2001] and dust [Tegen and Miller, 1998]). However, the aerosol species were independent of one another. The inclusion of heterogeneous chemistry, particularly of the condensation of gaseous precursors on aerosol surfaces, in aerosol models [Dentener et al., 1996; Bauer, 2005] made aerosol transformation and removal dependent on other species and contained some consideration of mixing state. Aerosol microphysical models that resolve such processes as new particle formation, coagulation, condensation, and cloud activation do potentially consider many processes that lead to internally mixed aerosols. However, due to the need to keep aerosol simulations computationally efficient, compromises had to be made when deciding on how to track this information. Most models are designed to keep track of the aerosol mass and number concentrations by using bin [Adams and Seinfeld, 2002; Spracklen et al., 2006] or modal [Whitby and McMurry, 1997; Easter et al., 2004] schemes. Even though model designs differ from one another, aerosols are commonly treated as either externally or internally homogenously mixed within one bin or mode. Exceptions are the sectional model by Jacobson [2002], which explicitly keeps track of aerosol mixing state, and the model used in this study, Goddard Institute for Space Studies (GISS) modelEMATRIX (Multiconfiguration Aerosol TRacker of mIXing state) [Bauer et al., 2008], a computationally efficient microphysical aerosol model designed for climate applications.
[6] The complexity of the problem and the difficulties in defining and observing aerosol mixing states make their evaluation an even greater challenge. This paper presents a first attempt at evaluating mixing states by comparing GISS modelE-MATRIX model findings to measurements made by an ATOFMS real-time single-particle mass spectrometer during five field campaigns. The campaigns took place in four locations in California and one location in South Korea during the years 2005-2009.

\section{Modeling Mixing State}

[7] The updated version of GISS modelE, which was prepared for GISS modelE contributions to the Coupled Model Intercomparison Project Phase 5 (CMIP5) archive, is used in this study. The model grid has horizontal and vertical resolutions ( $2^{\circ}$ latitude $\times 2.5^{\circ}$ longitude, 40 layers). In order to simulate similar tracer transport as observed during the field campaigns, model runs are nudged to the horizontal wind components of MERRA [Rienecker et al., 2011]. The model is run for the years 2000-2009 to cover the observational periods of field campaign data used in this study. Sea surface temperatures are prescribed as boundary conditions and the model is fully coupled to the gas-phase chemistry scheme. Dust and seawater emissions are calculated interactively in the model, while anthropogenic and biomass burning emissions are from the CMIP5 emission inventory by Lamarque et al. [2011].

[8] Aerosol processes in GISS modelE are calculated by the microphysical scheme MATRIX [Bauer et al., 2008, 2010]. MATRIX is based on the quadrature method of moments [Mcgraw, 1997], including two moments, number and mass, and one quadrature point. Carrying only two moments requires additional information about the shapes of the individual aerosol size distributions. We assume a lognormal distribution with constant width when calculating the initial size distributions, the conversion between aerosol mass and number concentration, emission distributions, coagulation rates, and aerosol optical properties. For each aerosol population (Table 1), defined by mixing state, the tracked variables are number concentration and mass concentration of sulfate, nitrate, ammonium, aerosol water, black carbon, organic carbon, mineral dust, and sea salt. MATRIX dynamics include new particle formation, particle emissions, gas-particle mass transfer, aerosol phase chemistry, condensational growth, coagulation, and cloud activation. An illustration of MATRIX size-resolved mixing state classes for distinctively different air mass types is presented in Appendix A.

\section{Observing Mixing State: Real-Time Single-Particle Mass Spectrometry}

[9] The aerodynamic size and chemical composition of individual particles between 0.1 and $3.0 \mu \mathrm{m}$ were measured in real time using ATOFMS. The design and details of ATOFMS have been reported by Gard et al. [1997], and a description is given in Appendix B. Single-particle size and mass spectral information were analyzed with YAADA 1.2 (www.yaada.org), a data analysis toolkit for MATLAB 6.5.1 (MathWorks, Inc.). Mass spectra were clustered using an adaptive-resonance-theory-based neural network algorithm 
Table 1. Definition of Mixing State in MATRIX: Population Definition, Geometric Mean Diameter at Emission Time Step, Name (as Used Hereafter), Chemical Composition, and Classification Compared to the ATOFMS Mixing State Classes ${ }^{\mathrm{a}}$

\begin{tabular}{|c|c|c|c|c|}
\hline Population Description & $\mathrm{Dg}, \mathrm{E}$ & Symbol & Constituents in Addition to $\mathrm{SO}_{4}{ }^{-2}, \mathrm{NO}_{3}{ }^{-}, \mathrm{NH}_{4}{ }^{+}, \mathrm{H}_{2} \mathrm{O}$ & ATOFMS Class \\
\hline Sulfate Aitken mode & 0.013 & AKK & & Sulfate/nitrate (other) \\
\hline Sulfate accumulation mode & 0.068 & $\mathrm{ACC}$ & & Sulfate/nitrate (other) \\
\hline Dust accumulation mode ( $\leq 5 \%$ inorganic) & 0.58 & DD1 & Dust & Fresh dust \\
\hline Dust accumulation mode ( $>5 \%$ inorganic) & & DS1 & Dust & Aged dust \\
\hline Dust coarse mode ( $\leq 5 \%$ inorganic) & 5.4 & DD2 & Dust & Fresh dust \\
\hline Dust coarse mode ( $>5 \%$ inorganic) & & DS2 & Dust & Aged dust \\
\hline Sea salt accumulation mode & 0.37 & SSA & Sea salt & Salts \\
\hline Sea salt coarse mode & 3.93 & $\mathrm{SSC}$ & Sea salt & Salts \\
\hline Organic carbon $(\mathrm{OC})$ & 0.03 & $\mathrm{OCC}$ & $\mathrm{OC}$ & $\mathrm{OC}$ \\
\hline Black carbon (BC) $(\leq 5 \%$ inorganic $)$ & 0.03 & $\mathrm{BC} 1$ & $\mathrm{BC}$ & Fresh EC \\
\hline $\mathrm{BC}(5 \%-20 \%$ inorganic $)$ & & $\mathrm{BC} 2$ & $\mathrm{BC}$ & Aged EC \\
\hline $\mathrm{BC}(>20 \%$ inorganic $)$ & & $\mathrm{BC} 3$ & $\mathrm{BC}$ & Aged EC \\
\hline $\mathrm{BC}-\mathrm{OC}$ & 0.037 & $\mathrm{BOC}$ & $\mathrm{BC}, \mathrm{OC}$ & $\mathrm{EC}-\mathrm{OC}$ \\
\hline BC-sulfate (formed by coagulation) & & BCS & $\mathrm{BC}$ & EC-sulfate \\
\hline BC-mineral dust & & $\mathrm{DBC}$ & Dust, BC & Dust-EC \\
\hline Mixed & & MXX & Dust, sea salt, $\mathrm{BC}, \mathrm{OC}$ & SS-EC, dust aged, salt, others \\
\hline
\end{tabular}

${ }^{\mathrm{a}}$ For comparison of the available data, the modeled black carbon is compared to the observed elemental carbon. EC and $\mathrm{BC}$ are used synonymously.

(ART-2a) at a vigilance factor of 0.8 and regrouped at a vigilance factor of 0.85 [Song et al., 1999]. General particle types are defined by the characteristic chemical species or possible source to simplify the naming scheme. ATOFMS counts were scaled to number concentrations using aerodynamic particle sizer (APS) size-resolved number concentrations, a method shown previously to yield quantitative mass concentrations [Qin et al., 2006]. For the Gosan study, SMPS data were used to expand the lower limit of the scaling by applying number fractions to the SMPS size distributions after correcting for density, an imperfect method necessary for comparisons near the mode of the number size distribution.

\section{Comparison Between ATOFMS and MATRIX}

[10] The following comparisons demonstrate the ability of MATRIX to reproduce the size-resolved chemical composition of aerosols in a number of environments: coastal marine, aged urban, fresh urban, and remote continental.

[11] ATOFMS data are used for a number of field campaigns between 2005 and 2009, as listed in Table 2. For this comparison, we have sampled the observations over the entire duration of each field campaign, which lasted between 9 and 45 days (average of 22 days). The model was sampled for the same time episodes. To allow comparisons between ATOFMS and MATRIX, the data sets had to be merged into similar mixing state definitions. The grouping of MATRIX populations into the ATOFMS classes is shown in Table 1. The general ATOFMS classes of fresh elemental carbon (EC) (soot), elemental carbon/organic carbon (ECOC), organic carbon (OC), sea salt, mineral dust, and mixtures account for $>85 \%$ of particles from 0.1 to $3.0 \mu \mathrm{m}$ in studies across the Northern Hemisphere. To bring the model categories and ATOFMS classes into agreement, ATOFMS clusters were recategorized based on the following distinctions: Fresh EC went into BC1, ECOC went into EC$\mathrm{OC}$, biomass burning and $\mathrm{OC}$ went into OCC, sea salt went into SSA or SSC (depending on size), fresh dust with minimal markers for aging (i.e., nitrate) went into DD1 and DD2 as a function of size, and aged dust with nitrate went into DS1 and DS2 as a function of size. Spectra with no positive signal and intense sulfate peaks went into $\mathrm{ACC}$, mixtures of EC with dust into DBC, and mixtures of carbonaceous and mechanically generated particles (i.e., EC with SS/ dust) into MXX, but none of these categories were significant number fractions at any size sampled. Modeled particle sizes have been converted into aerodynamic size by taking into account the density of the aerosol mixture.

\subsection{La Jolla, California}

[12] Measurements made at the end of the Scripps Institution of Oceanography (SIO) pier ( $\sim 300 \mathrm{~m}$ offshore) in 2006 provide a representative example of a coastal marine location with urban influences, which due to the diurnal wind

Table 2. ATOFMS Study Details

\begin{tabular}{|c|c|c|c|c|c|c|}
\hline Study Location & Abbreviation & Study & Latitude & Longitude & Period & References \\
\hline $\begin{array}{l}\text { Riverside, California, } \\
\text { USA }\end{array}$ & SOAR LABMS1 & $\begin{array}{c}\text { Study of Organic Aerosols } \\
\text { in Riverside Los Angeles } \\
\text { Mobile Study } 1\end{array}$ & 33.97 & -117.32 & $\begin{array}{c}\text { 30 Jul. to } 15 \\
\text { Aug. } 2005,29 \\
\text { Aug. to } 7 \text { Sep. } 2007\end{array}$ & $\begin{array}{l}\text { Moffet et al. [2008], } \\
\text { Ault et al. }[2009], \\
\text { Gaston et al. [2010] }\end{array}$ \\
\hline $\begin{array}{l}\text { La Jolla (San Diego), California, } \\
\text { USA }\end{array}$ & SIO Pier & $\begin{array}{c}\text { Scripps Oceanography } \\
\text { Pier Study }\end{array}$ & 32.87 & -117.26 & $\begin{array}{l}18 \text { Aug. } \\
\text { to } 1 \text { Oct. } 2006\end{array}$ & Ault et al. [2009] \\
\hline Gosan, Jeju, South Korea & PACDEX & Pacific Dust Experiment & 33.29 & 126.18 & $\begin{array}{l}13 \text { Apr. } \\
\text { to } 15 \text { May } 2007\end{array}$ & Ault and Pomeroy [2012] \\
\hline Los Angeles, California, USA & LABMS2 & Los Angeles Mobile Study 2 & 33.74 & -118.27 & 17-26 Nov. 2007 & Ault et al. [2010] \\
\hline Sugar Pine, California, USA & Calwater & Calwater Early Start & 39.13 & -120.80 & $\begin{array}{l}21 \mathrm{Feb} . \\
\text { to } 11 \mathrm{Mar} .2009\end{array}$ & $\begin{array}{c}\text { Ault et al. }[2011], \\
\text { Creamean et al. }[2011]\end{array}$ \\
\hline
\end{tabular}


patterns did not experience significant stagnation [Ault et al., 2009]. Figure 1a shows size-resolved number concentration data averaged over the course of the study. The supermicron size range is dominated by sea-salt particles, with the mode peaking at roughly $1.1 \mu \mathrm{m}$. Below $1 \mu \mathrm{m}$, a transition is observed toward predominantly carbonaceous aerosols, which dominate the overall number concentration below $0.6 \mu \mathrm{m}$. The diameter of the transition from $>50 \%$ mechanically generated aerosols (i.e., sea salt and mineral dust) to $>50 \%$ carbonaceous aerosols (soot, organic carbon, etc.), $d_{\text {carb }}$, has been identified as a useful parameter for evaluating how important sources other than sea salt and dust are on a site. For the SIO study, this value occurs at $0.64 \mu \mathrm{m}$. In this environment, the vast majority of carbonaceous particles contain elemental carbon (or soot) mixed with such secondary species as sulfate, nitrate, organic carbon, and water and there is no significant externally mixed population of organic carbon particles above $0.5 \mu \mathrm{m}$.

[13] Comparison between ATOFMS and MATRIX (Figure 1) shows a remarkable agreement between the model and the observations, in terms of both number concentration and single-particle composition. Among the key features in agreement between the model and the measurements are that the supermicron sea-salt mode peaks at $1.1 \mu \mathrm{m}$ and that carbonaceous species dominate below $0.6 \mu \mathrm{m}$. There are also a few noteworthy differences that have been observed between the model and the measurements, including a lack of mineral dust in ATOFMS measurements compared to MATRIX predictions, the relative contribution of purely organic carbon versus aged soot to the carbonaceous mode below $0.6 \mu \mathrm{m}$, and a lack of fresh EC. The modeled dust originated from Mexico and was transported to this location carrying sulfate, ammonia, and nitrate coatings on its surface. This discrepancy may be due in part to the comparison of a grid cell size area having significant impacts from dust to a site that has minimal impact from dust except under strong offshore wind conditions (Santa Ana events) [Guazzotti et al., 2001]. Mixing state classes of particles sized between 0.5 and $1 \mu \mathrm{m}$ are dominated by mixtures incorporating organics. The largest fraction is ECOC, followed by $\mathrm{OC}$ and partial contributions of EC-sulfate, which is larger in the observations than in MATRIX. The lack of fresh EC (low sulfate, nitrate, or organic carbon loadings) is simulated at all locations shown in Figure 1 and likely due to local sources not captured by the model or averaged out over the size of the grid cell. Capturing fresh $\mathrm{EC}$ and understanding its aging in models and measurements at the same sites are an ongoing challenge that calls for further efforts between modelers and experimentalists. We will revisit this topic later for the Jeju case, where we can compare mixing state information between ATOFMS and MATRIX for smaller particle sizes.

\subsection{Riverside, California}

[14] In contrast to San Diego, where diurnal winds serve to prevent stagnation, Riverside, California, is one of the most prominent examples of a location where air masses stagnate, allowing for extensive formation of secondary organic aerosols [Docherty et al., 2008; Pratt and Prather, 2009; Qin et al., 2012]. Data from the summer of 2005 (Figure 1b) show a substantially different single-particle composition, with the organic carbon particles representing the majority of particles below $1.4 \mu \mathrm{m}$, with the rest coming from fresh EC and ECOC [Qin et al., 2012]. The $d_{\text {carb }}$ transition to the majority being mechanically generated particles occurs at $1.4 \mu \mathrm{m}$, a much higher value than that for San Diego, indicating that supermicron carbonaceous particles are a significant fraction of supermicron mass in stagnant locations. In contrast to 2005, the data from Riverside in 2007 (Figure 1c) show a period with much lower PM concentrations and a greatly reduced contribution of carbonaceous particles above $1 \mu \mathrm{m}$ [Ault et al., 2010]. A sea-salt mode that peaks at $1.2 \mu \mathrm{m}$, observed in both San Diego and Riverside during 2005, dominates the supermicron micron number fraction. Due to the high winds that resulted in less stagnant conditions, mineral dust is $5 \%-15 \%$ of the number fraction between 0.5 and $3.0 \mu \mathrm{m}$. Below $1 \mu \mathrm{m}$, internally mixed ECOC is the greatest contributor to the number concentration, with smaller contributions from fresh EC and OC particles. These studies show that while the intensity of the carbonaceous particle dominating the number size distribution varies in Riverside, the mechanically generated sea-salt and dust concentrations are reasonably consistent under different meteorological conditions.

[15] Very similar distributions from ATOFMS and MATRIX are shown for Riverside (Figures $1 \mathrm{~b}$ and 1c). During the 2005 field observational period, MATRIX shows a smaller number concentration, but particles below $1 \mu \mathrm{m}$ are primarily ECOC particles, OC, and a small fraction of ECsulfate, with good agreement as to their relative contributions. Similarly, the model captures a transition to sea salt and dust above $1 \mu \mathrm{m}$, although the diameter at which this occurs is smaller than that for the ATOFMS measurements. Additionally, MATRIX finds a significant contribution of sea salt and mineral dust down to $0.5 \mu \mathrm{m}$ that is not observed in the ATOFMS measurements. During the 2007 period, MATRIX captured smaller contributions of pollution aerosols and modes of sea salt and mineral dust. MATRIX does show a slightly higher fraction of dust, while the partitioning between fresh dust and aged dust shows more fresh dust than the measurements indicate. Interestingly, both examples show a small fraction of sulfate aerosols (marked in yellow). Overall, MATRIX does well at representing the single-particle composition of the number size distribution for a location that has conditions ranging from extremely stagnate and polluted to relatively clean under high wind conditions.

\subsection{Long Beach, California}

[16] A challenging location to sync measurements and models is a region with multiple intense and rapidly evolving sources, such as the region surrounding the ports of Los Angeles and Long Beach [Krudysz et al., 2009]. Measurements on Terminal Island in the fall of 2007 represent an extreme case, with diurnal wind patterns preventing stagnation but extensive sources from shipping, trucking, and industry (i.e., oil refineries) leading to extremely polluted conditions [Minguillón et al., 2008; Krudysz et al., 2009; Ault et al., 2010]. Here ATOFMS data show high concentrations of fresh EC and ECOC dominating the number size distribution below $1.4 \mu \mathrm{m}$ and that, unlike in Riverside, purely organic carbon particles make up less than $5 \%$ of aerosols in all bins above $0.5 \mu \mathrm{m}$. The sea-salt 

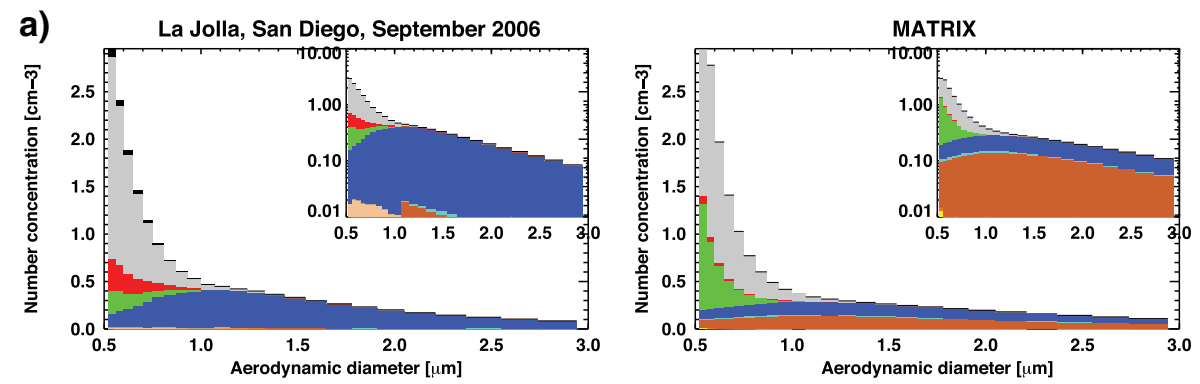

\section{EC fresh}

EC-OC

EC-Sulfate

OC

Salts

DustSupFresh

DustSupAged

b)

Riverside, CA July-August 2005
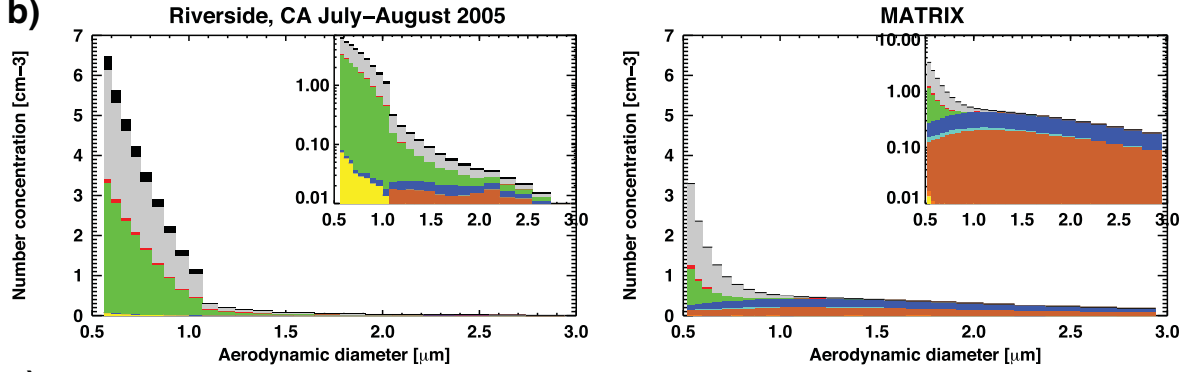

c)
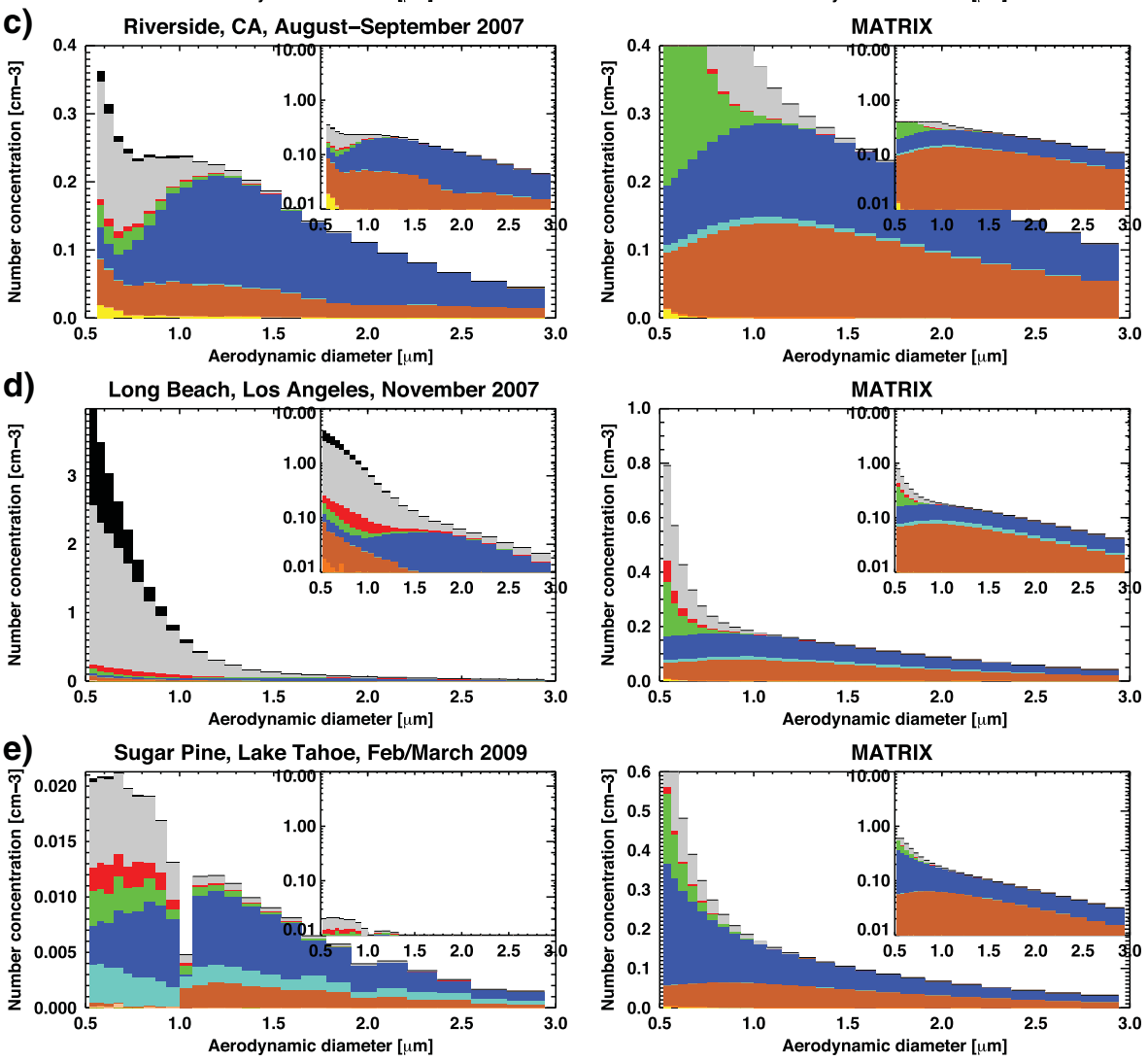

Figure 1. Size-resolved number concentrations of color-coded mixing state classes are shown for particle size bins between 0.5 and $3 \mu \mathrm{m}$. The inserted graphs show the same distributions but on a $y$-log axis. ATOFMS (left) and MATRIX (right column) results are shown for five field campaigns: (a) one in La Jolla, (b and c) two in Riverside, and one each in (d) Long Beach and (e) Sugar Pine.

mode observed in the previous locations is observed again at $\sim 1.3 \mu \mathrm{m}$, but — as with Riverside in 2005 — the anthropogenic particles dominate the distribution.

[17] The source site represented is very spatially homogeneous. The model did not capture these features and involved more general background conditions, similar to those observed for Riverside in 2005. Given the large number of high-intensity sources, the ports of Los Angeles and
Long Beach represent a site influenced by local pollution that cannot be captured by the general circulation model grid boxes.

\subsection{Sugar Pine, California}

[18] A second challenging location with extremely low particle concentrations is a remote continental site. Measurements at the Sugar Pine Reservoir in Forest Hill, California, a remote 


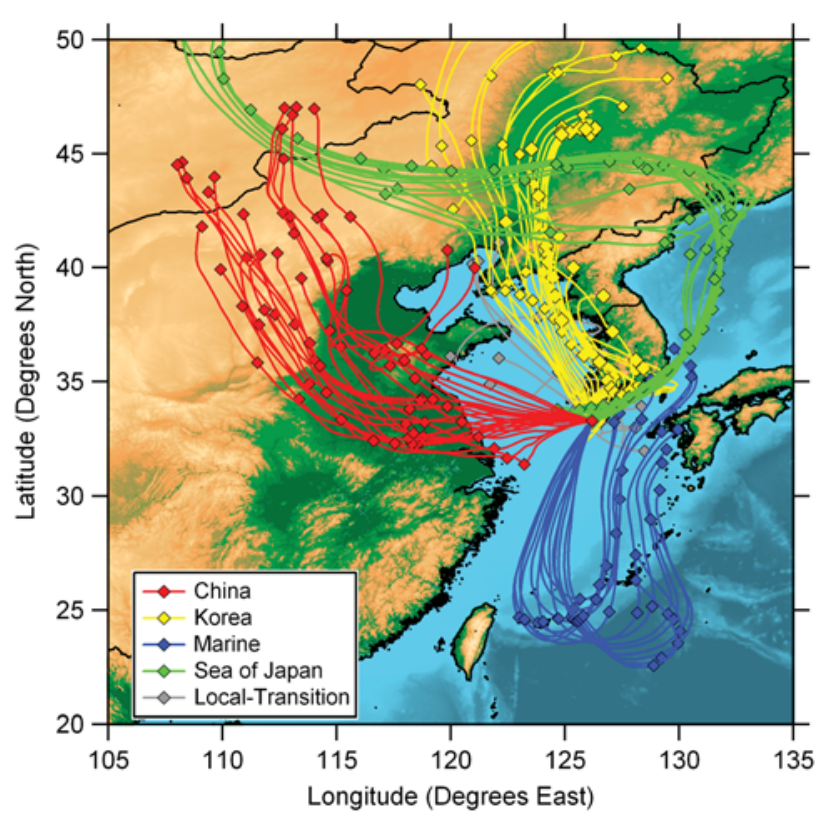

Figure 2. Size-resolved number concentrations of mixing state classes for particles between 0.07 and $0.5 \mu \mathrm{m}$ in Jeju, South Korea, for ATOFMS (left) and MATRIX (right). The inserted boxes show the entire range of measured size distribution on a log scale. Averaged mixing state conditions are shown for four air mass types originating from (a) a marine site, (b) Eastern China, (c) Korea, and (d) the Gobi desert.

rural site in the Sierra Nevada Mountains (elevation, $1064 \mathrm{~m}$ ASL) [Ault et al., 2011; Creamean et al., 2011], provide an ideal test case for evaluating MATRIX in such a location. In comparison to Long Beach, which routinely has number concentrations $>10,000 \mathrm{H} / \mathrm{cm}^{3}$ [Krudysz et al., 2009], number concentrations at Sugar Pine averaged $240 \mathrm{\#} / \mathrm{cm}^{3}$ [Creamean et al., 2011], roughly 2 orders of magnitude lower. The number size distributions at Sugar Pine were frequently dominated by new particle formation events, meaning that nearly all of the number concentrations were below $0.15 \mu \mathrm{m}$ [Creamean et al., 2011]. Thus, the very few particles $>0.5 \mu \mathrm{m}$ led to the low concentrations shown in Figure 1e. In the supermicron range, much of the particle concentration is composed of sea salt and a mix of fresh dust and aged dust, while below $1 \mu \mathrm{m}, \mathrm{ECOC}, \mathrm{OC}$, and ECsulfate comprise the majority of the particles. The sea-salt mode results from long-range transport to the site [Ault et al., 2011] and is at the same diameter as observed in the other locations. A shift is observed from equal parts aged dust and fresh dust in the supermicron to primarily fresh dust in the submicron.

[19] For the remote continental site, MATRIX does a good overall job of capturing the different particle compositions and their sizes. In the supermicron mode, the composition is dominated by dust and sea salt in similar proportions to the ATOFMS measurements, although all dust is observed as aged due to the model only considering desert dust sources. Below $1 \mu \mathrm{m}$, contributions from ECOC, EC-sulfate, and OC are shown, with little fresh EC matching the ATOFMS measurements, at roughly similar relative proportions. The shape of the dust distribution in MATRIX matches the ATOFMS observations. The challenge of grid size is observed again, although in this case with much higher concentrations in MATRIX than in measurements versus the opposite trend observed at the ports of Los Angeles and Long Beach. This is logical as other sources exist in the grid cell (such as I-80 and several small cities) and Sugar Pine was chosen to be as pristine a site as possible. However, from a fractional perspective, MATRIX does well for a very challenging site.

\subsection{Jeju, South Korea}

[20] To test the agreement between MATRIX and singleparticle measurements closer to the peak of the number size distribution, data from Gosan, South Korea, in 2007 are shown in Figure 2. The island is impacted by air masses containing particles from a wide range of source regions (Figure 3), including heavily polluted air masses from Eastern China, less polluted air masses from the mainland of Korea, air masses from the Gobi desert, and marine air masses. The number size distributions peaked between 0.067 and $0.111 \mu \mathrm{m}$ depending on the air mass types. ATOFMS data down to $0.1 \mu \mathrm{m}$ give a good indication as to the different single-particle compositions likely to be present at the mode of the distribution. It is interesting to observe that mixing state classes do not dramatically change between the four air mass cases: marine, East China, Korea, and Gobi desert. Typically, the composition includes a small fraction of dust (except in the marine case), a large contribution from internally mixed OC, having EC and sulfate, and a substantial contribution of fresh EC (due to local sources). The $d_{\text {carb }}$ is observed at roughly $1 \mu \mathrm{m}$, above which sea salt and dust become dominant. Of particular note is that the greatest difference between the air mass types is seen in the absolute number concentrations, which are highest when the air mass has spent time over Eastern China and lowest for the marine back trajectory. MATRIX does well at capturing the differences in number concentration between the four cases. However, even with these wide ranges in number concentration, the composition of particles $<0.5 \mu \mathrm{m}$ does not change significantly, which is important for how marine regions are modeled generally. This is caused by the fact that Gosan experiences relatively aged air masses. It is important to note the lack of pure OC particles, which are often assumed to be large contributors to the submicron aerosol in remote locations. ATOFMS and MATRIX show a significant contribution of fresh EC. Fresh EC, which has been detected by ATOFMS (Figure 1), is now finally visible in MATRIX as well because we are comparing smaller aerosol size classes in this case while in a region that is generally very high in black carbon emissions. Fresh EC coagulates and attracts coatings quickly, allowing fresh $\mathrm{EC}$ in the model only to be visible around its emission sizes. Larger EC that has already aged will always appear in mixed EC size classes. Thus, the apparent lack of consistency between ATOFMS and MATRIX measurements for the studies in Figure 1 is likely definitional and does not represent significantly different results.

[21] Figure 4 shows the total number concentrations for particles between 0.5 and $3 \mu \mathrm{m}$ for all six field campaigns. For number concentrations above $5 \mathrm{~cm}^{-3}$, the model and observations show similar scatter. For concentrations below $5 \mathrm{~cm}^{-3}$, mostly representing supermicron aerosols, the 
a)

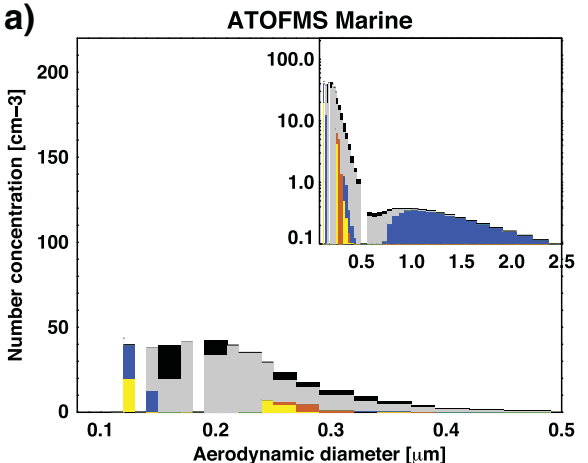

b)

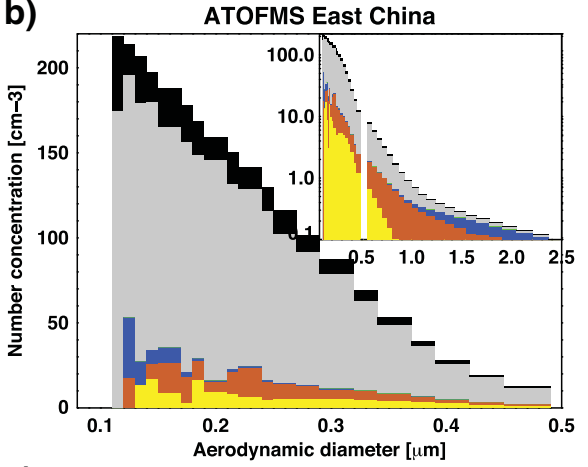

c)

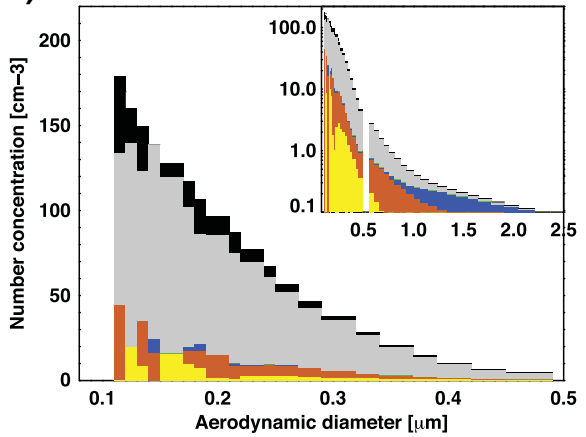

d)

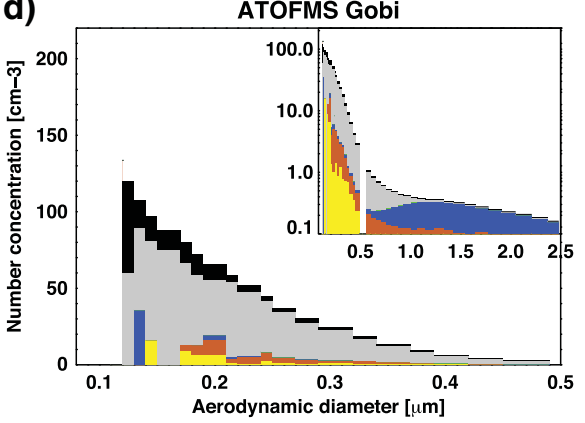

MATRIX Marine

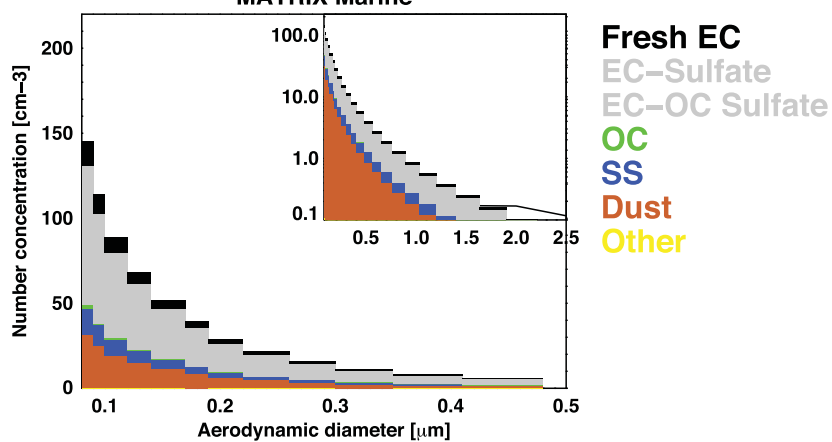

MATRIX China

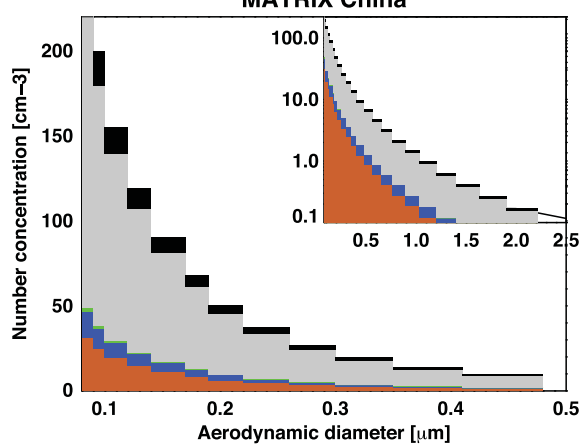

MATRIX Korea

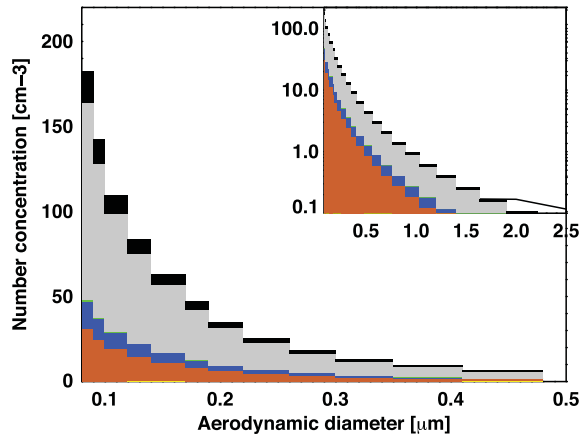

MATRIX Gobi/Manchuria

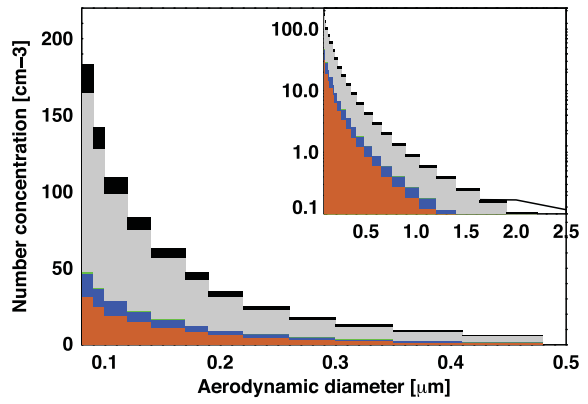

Figure 3. Back trajectories of air mass types as observed in Jeju, South Korea, between 12 April and 15 May 2007.

model tends to underestimate EC-sea salt and EC-dust mixtures, while aged dust, fresh dust, and salts in this concentration range are overestimated. Dust and sea salt are the aerosol types that spread over all size ranges. MATRIX has to resolve the size distributions and mixing state of dust with six populations and those of sea salt with three. These resolutions might not be enough to represent all possible size and mixing state options precisely. Furthermore, we only emit dust and sea salt into two size classes, which is a simplified assumption. Lastly, the definitions of mixing state classes between the measurements and the model are not identical and are only approximated.

\section{Discussion}

[22] The microphysical details that are necessary to simulate realistic aerosol mixing states require the model to have good skills in general aerosol simulation, such as aerosol mass by chemical species, number concentrations, and aerosol size. From prior [Bauer et al., 2008, 2010, 2013] 


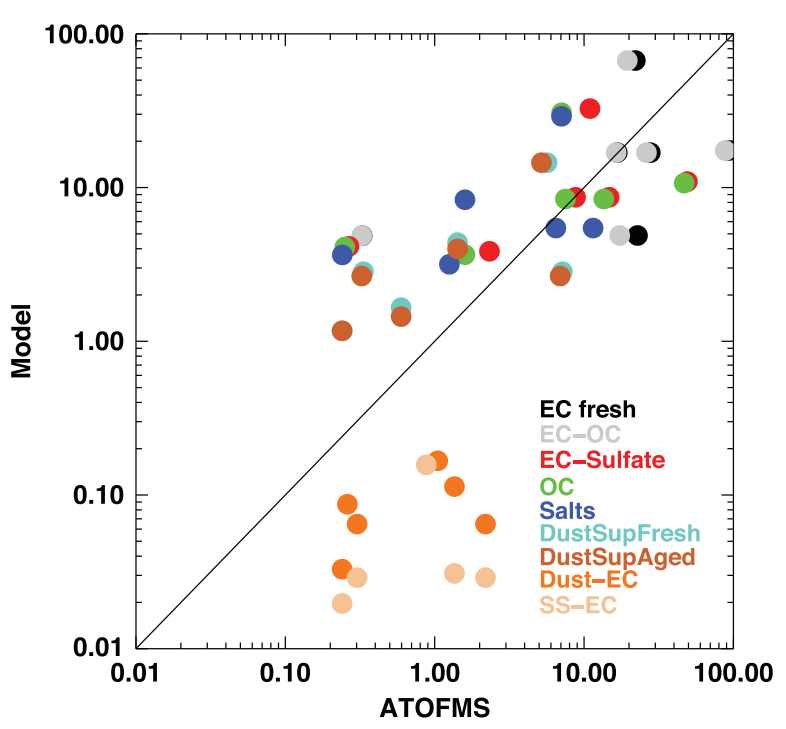

Figure 4. Scatter plot between model and ATOFMS total number concentrations (summed over $0.5-3.0 \mu \mathrm{m}$ ) per mixing state in $\mathrm{cm}^{-3}$. All stations from Figure 1 and Jeju are presented. The color coding indicates the mixing state classes.

and ongoing evaluations through the AeroCom initiative (http://aerocom.met.no), we have learned the strengths and weaknesses of MATRIX relative to those of other global aerosol models. Therefore, we are pleased to learn from this study that comparisons between a coarse global climate model and detailed field measurements at single locations are possible. Averaging the field campaign data over the duration of the campaign, typically a couple of weeks, allowed for the characterization of typical air masses and mixing state classes at each location. Further nudging the model with reanalysis data allowed the comparison of similar air mass types that have been transported to the observed location. Although not discussed in this paper, conducting a similar comparison using a climatological model run (10 year mean conditions of a free-running, nonnudged model experiment) found mostly similar results as presented in this study. Hence, we conclude that observations taken over a period of 1 month sufficiently characterize typical air mass types at a given location.

[23] This comparison has demonstrated that at the four locations in California, three in polluted areas (Riverside, La Jolla, and Long Beach) and one in a remote location in Sugar Pine, the great majority of aerosol species are internally mixed. Coarse aerosol particles, above $1 \mu \mathrm{m}$, tend to be mechanically produced and aged, such as coated mineral dust or heterogeneously reacted sea-salt particles. Particles below $1 \mu \mathrm{m}$ contain large fractions of organic material and appear in mixing states that include organics such as ECOC and OC. No externally mixed sulfate or nitrate was observed or simulated in the presented examples in particles larger than $0.5 \mu \mathrm{m}$. Observations in Jeju, South Korea, allowed us to compare particles down to $0.1 \mu \mathrm{m}$. At these smaller sizes, MATRIX could detect more fresh EC, in agreement with the measurements. Overall, the ATOFMS definition of fresh EC (carbon cluster peaks in the positive and negative mass spectra, with greater intensity than $\mathrm{OC}$ or sulfate peaks) and MATRIX definition of fresh EC
$(<5 \%$ inorganic and no OC) were not in complete agreement (as seen in Figure 3) but converged at lower sizes where more fresh EC is present in the model (Figure 2). Finding definitions that can help lead to convergence is both challenging and necessary given the importance of representing EC/soot mixing state properly for climate impacts [Jacobson, 2002; Riemer et al., 2009].

[24] This study is limited by the fact that we only compared number concentrations of mixing state classes above $0.5 \mu \mathrm{m}$ (and in the Korea case, above $0.07 \mu \mathrm{m}$ ) diameters. Particles above $0.5 \mu \mathrm{m}$ have already aged significantly through condensation and coagulation processes. Also, we did not compare mass budgets in this study. As a logical next step, we would like to evaluate the mixing states of fine and coarse aerosol concentrations to close mass and number budgets. A multi-instrument analysis is most suitable to deal with a complex aerosol property such as mixing state. For example, the combination of state-of-the-art single-particle mass spectrometer instruments such as a single-particle mass spectrometer (SPLAT II [Zelenyuk et al., 2009]), the particle analysis by laser mass spectrometer (PALMS [Murphy et al., 1998]), a single-particle soot photometer (SP2 [Schwarz et al., 2008]), and the aerosol time-of-flight mass spectrometer (ATOFMS [Pratt et al., 2009]) used in this study can provide a more complete picture of the different particle types and mixing states present in a population of aerosols. Aerosol properties such as density, optical properties, shape, number concentrations, and size distributions [Zaveri et al., 2012] as well as data from other sources to determine composition as a function of hygroscopicity and CCN activity, among others, will further provide insight into the aerosol mixing state and its relevance for climate simulations.

[25] Resolving mixing state in climate models, especially when attempting to answer questions regarding which emission source is responsible for air pollution or climate impacts, is of great importance. Instruments such as ATOFMS provide unique details for identifying the potential sources of aerosols (e.g., vehicular emissions and biomass burning) as well as their degrees of aging. The combination of observations and models that can resolve such chemical details is required for advancing climate and policy studies.

\section{Appendix A: Examples of Mixing State Representation}

[26] In order to illustrate the definitions of MATRIX mixing state classes, Figure A1 presents size-resolved aerosol population examples of different air mass types. Four examples of annual mean mixing state conditions at the surface level are presented for marine (close to Hawaii), desert (Sahara, Mali), biomass burning (Brazil), and urban pollution (Beijing) grid cells. The size-resolved fraction of the chemical composition is given for the seven components of the aerosol populations. Aerosol water, which is not shown in this plot, contributes to $79 \%, 1 \%, 31 \%$, and $77 \%$ of the total aerosol mass in the chosen examples, respectively. Small particles, below $0.1 \mu \mathrm{m}$, in the remote marine location are composed of sulfate and ammonium, represented in the Aitken and accumulation (AKK and ACC) populations. Sea salt is the dominant chemical species of particles larger than $0.1 \mu \mathrm{m}$ and represented in the SSA, SSC, and MXX populations. MXX at this location mostly includes sea salt 


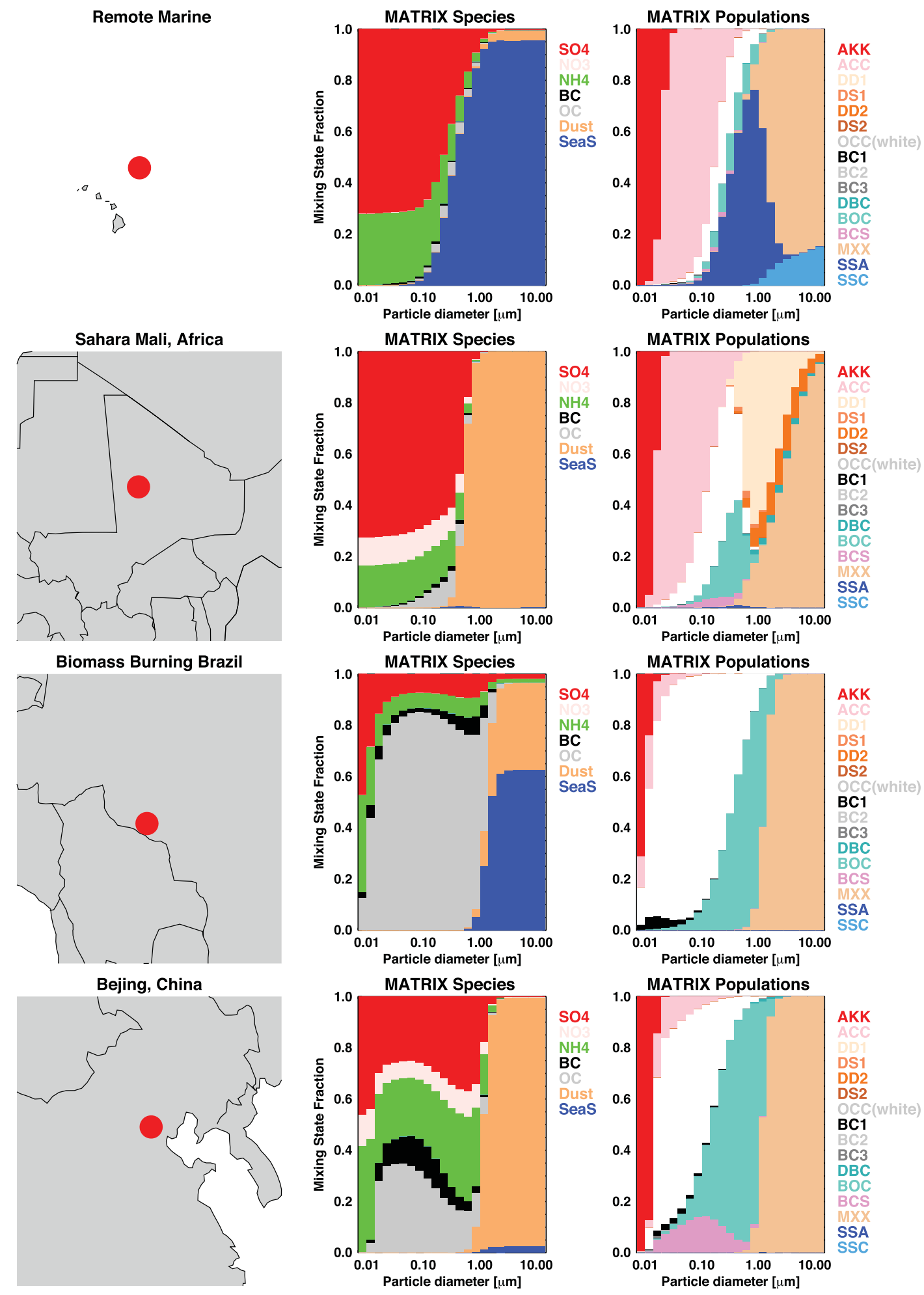

Figure A1. Aerosol mixing state samples of various air mass types: remote marine (Hawaii), desert (Mali), biomass burning (Gabon, Brazil), and urban (Beijing). Size distributions (geometric diameter in micrometers) of mixing state fractions are given per chemical species (sulfate, nitrate, ammonium, $\mathrm{BC}$, OC dust, and sea salt) and aerosol population (population acronyms are defined in Table 1).

and a small fraction of dust. Small particles in the desert example are composed of sulfate, ammonia, nitrate, and organic carbon, with a small fraction of black carbon. Larger particles are completely dominated by dust minerals.
The larger particles are dominated by different mixing states of desert dust. These include small and large dust classes with thin (DD1 and DD2) and thick (DS1 and DS2) coatings, a small fraction of BC-dust mixtures, and, finally, MXX, 
which in this location primarily contains dust but with larger coatings than those that can be accommodated in DS1 or DS2. The location picked in Brazil experiences frequent biomass burning events. This leads to a high concentration of $\mathrm{OC}$ in the aerosol mix resulting in $\mathrm{OCC}, \mathrm{BC} 1$, and $\mathrm{BOC}$ populations for aerosols of sizes between 0.1 and $1 \mu \mathrm{m}$. Coarse particles are composed of a mix of dust and sea salt with small fractions of inorganic species. Beijing accommodates larger fractions of carbonaceous aerosols compared to the previous examples and the larger particles are dominated by desert dust. The higher $\mathrm{BC}$ and $\mathrm{OC}$ concentrations lead to the spread of OCC, BOC, and BCS into the small aerosol size classes $(0.1 \mu \mathrm{m})$. Additionally, nearly pure $\mathrm{BC}$, population $\mathrm{BC} 1$, can be observed.

[27] These examples are given to visualize how mixing state is represented in the model, over the size classes we resolve, from 0.03 to $20 \mu \mathrm{m}$. The mixing state comparisons between the measurements and the model presented in this paper only allow comparing the size classes that can be observed by ATOFMS, which in most cases are coarse aerosol fractions above $0.5 \mu \mathrm{m}$ and in one case cover particles from 0.07 to $3 \mu \mathrm{m}$.

\section{Appendix B: Aerosol Time-of-Flight Mass Spectrometry}

[28] Particles are introduced into the ATOFMS through a converging nozzle into a differentially pumped vacuum chamber where they are accelerated to a terminal velocity [Gard et al., 1997]. The particles then pass through two continuous wave lasers (diode-pumped Nd:YAG lasers operating at $532 \mathrm{~nm}$ ) located $6 \mathrm{~cm}$ apart. The aerodynamic diameter of each particle is determined through calibration with polystyrene latex spheres of known aerodynamic size, shape, and density. The sized particles are then desorbed and ionized by irradiation from a Q-switched Nd:YAG laser (266 nm, 1.2$1.4 \mathrm{~mJ} /$ pulse) that is triggered when the particle is in the center of the mass spectrometer ion source region. Positive and negative ions from each particle are detected using a dual-polarity reflectron time-of-flight mass spectrometer. These labels do not reflect all of the species present within a specific particle type but do reflect the most intense ion peaks.

[29] The scaling to number concentrations is done as follows: ATOFMS counts are binned into sizes that correspond to the aerodynamic particle sizer (APS) bins $(0.5-2.5 \mu \mathrm{m})$ and scaling factors for each hour and size bin are determined to account for ATOFMS transmission biases and busy time. Each bin is then scaled to give number concentrations.

[30] Acknowledgments. This research was supported by the NASA MAP program Modeling, Analysis, and Prediction of Climate Variability and Change (NN-H-04-Z-YS-008-N and NN-H-08-Z-DA-001-N). Resources supporting this work were provided by the NASA High-End Computing (HEC) Program through the NASA Center for Climate Simulation (NCCS) at Goddard Space Flight Center. Funding for the field studies discussed came from the California Air Resources Board (CARB) (Los Angeles, Riverside, and San Diego), California Energy Commission (CEC) (Sugar Pine), and Atmospheric Brown Clouds project under the United Nations Environmental Program (ABC) (Gosan, Korea). A.A. is grateful for a Department of Energy Global Change Education Program Graduate Research Environmental Fellowship (GCEP-GREF). Jessie Creamean, Cassandra Gaston, Xueying Qin, Steve Toner, Ying Wang, and Aihua Zhu are thankfully acknowledged for their contributions during data collection. V. Ramanathan and S. Yoon are thanked for their role in the Gosan measurements.

\section{References}

Adachi, K., S. H. Chung, and P. R. Buseck (2010), Shapes of soot aerosol particles and implications for their effects on climate, J. Geophys. Res., 115, D15206, doi:10.1029/2009JD012868.

Adams, P. J., and J. H. Seinfeld (2002), Predicting global aerosol size distributions in general circulation models, J. Geophys. Res., 107(D19), 4370, doi:10.1029/2001JD001010.

Ault, A. P., and R. Pomeroy (2012), Quantitative investigations of biodiesel fuel using infrared spectroscopy: An instrumental analysis experiment for undergraduate chemistry students, J. Chem. Educ., 89(2), 243-247, doi:10.1021/ed101097n.

Ault, A. P., M. J. Moore, H. Furutani, and K. A. Prather (2009), Impact of emissions from the Los Angeles port region on San Diego air quality during regional transport events, Environ. Sci. Technol., 43(10), 3500-3506, doi:10.1021/es8018918.

Ault, A. P., C. J. Gaston, Y. Wang, G. Dominguez, M. H. Thiemens, and K. A. Prather (2010), Characterization of the single particle mixing state of individual ship plume events measured at the port of Los Angeles, Environ. Sci. Technol., 44(6), 1954-1961, doi:10.1021/es902985h.

Ault, A. P., C. R. Williams, A. B. White, P. J. Neiman, J. M. Creamean, C. J. Gaston, F. M. Ralph, and K. A. Prather (2011), Detection of Asian dust in California orographic precipitation, J. Geophys. Res., 116, D16205, doi:10.1029/2010JD015351.

Bauer, S. E. (2005), Impact of heterogeneous sulfate formation at mineral dust surfaces on aerosol loads and radiative forcing in the Goddard Institute for Space Studies general circulation model, J. Geophys. Res., 110, D17202, doi:10.1029/2005JD005870.

Bauer, S. E., M. I. Mishchenko, A. A. Lacis, S. Zhang, J. Perlwitz, and S. M. Metzger (2007), Do sulfate and nitrate coatings on mineral dust have important effects on radiative properties and climate modeling? J. Geophys. Res., 112, D06307, doi:10.1029/2005JD006977.

Bauer, S. E., D. L. Wright, D. Koch, E. R. Lewis, R. Mcgraw, L. S. Chang, S. E. Schwartz, and R. Ruedy (2008), MATRIX (Multiconfiguration Aerosol TRacker of mIXing state): An aerosol microphysical module for global atmospheric models, Atmos. Chem. Phys., 8(20), 6003-6035.

Bauer, S. E., S. Menon, D. Koch, T. C. Bond, and K. Tsigaridis (2010), A global modeling study on carbonaceous aerosol microphysical characteristics and radiative effects, Atmos. Chem. Phys., 10(15), 7439-7456, doi:10.5194/acp-10-7439-2010.

Bauer, S. E., A. Bausch, L. Narzarenko, K. Tsigaridis, B. Xu, R. Edwards, M. Bisiaux, and J. McConnell (2013), Historic and future black carbon deposition on the three ice caps: Ice-core measurements and model simulations from 1850 to 2100, J. Geophys. Res. Atmos., 118, 1-14, doi:10.1002/jgrd.50612.

Carson, P. G., K. R. Neubauer, M. V. Johnston, and A. S. Wexler (1995), On-line chemical analysis of aerosols by rapid single-particle mass spectrometry, J. Aerosol Sci., 26(4), 535-545, doi:10.1016/0021-8502 (94)00133-J.

Creamean, J. M., A. P. Ault, J. E. Ten Hoeve, M. Z. Jacobson, G. C. Roberts, and K. A. Prather (2011), Measurements of aerosol chemistry during new particle formation events at a remote rural mountain site, Environ. Sci. Technol., 45(19), 8208-8216, doi:10.1021/es103692f.

Dentener, F. J., G. R. Carmichael, Y. Zhang, J. Lelieveld, and P. J. Crutzen (1996), Role of mineral aerosol as a reactive surface in the global troposphere, J. Geophys. Res., 101(D17), 22,869-22,889, doi:10.1029/ 96JD01818.

Docherty, K. S., et al. (2008), Apportionment of primary and secondary organic aerosols in Southern California during the 2005 Study of Organic Aerosols in Riverside (SOAR-1), Environ. Sci. Technol., 42(20), 7655-7662, doi:10.1021/es8008166.

Easter, R. C., S. J. Ghan, Y. Zhang, R. D. Saylor, E. G. Chapman, N. S. Laulainen, H. Abdul-Razzak, L. R. Leung, X. D. Bian, and R. A. Zaveri (2004), MIRAGE: Model description and evaluation of aerosols and trace gases, J. Geophys. Res., 109, D20210, doi:10.1029/ 2004JD004571.

Gard, E., J. E. Mayer, B. D. Morrical, T. Dienes, D. P. Fergenson, and K. A. Prather (1997), Real-time analysis of individual atmospheric aerosol particles: Design and performance of a portable ATOFMS, Anal. Chem., 69(20), 4083-4091, doi:10.1021/ac970540n.

Gaston, C. J., K. A. Pratt, X. Y. Qin, and K. A. Prather (2010), Real-time detection and mixing state of methanesulfonate in single particles at an inland urban location during a phytoplankton bloom, Environ. Sci. Technol., 44(5), 1566-1572, doi:10.1021/es902069d.

Guazzotti, S. A., J. R. Whiteaker, D. Suess, and K. R. Coffee (2001), Realtime measurements of the chemical composition of size-resolved particles during a Santa Ana wind episode, California USA, Atmos. Environ., 35(19), 3229-3240, doi:10.1016/S1352-2310(01)00140-6.

IPCC (2007), Fourth Assessment Report: Climate Change 2007 Contribution of Working Group I to the Fourth Assessment Report of the 


\section{BAUER ET AL.: AEROSOL MIXING STATE}

Intergovernmental Panel on Climate Change, 2007, edited by S. Solomon, Cambridge University Press, Cambridge, United Kingdom and New York, NY, USA.

Jacobson, M. Z. (2002), Analysis of aerosol interactions with numerical techniques for solving coagulation, nucleation, condensation, dissolution, and reversible chemistry among multiple size distributions, J. Geophys. Res., 107(D19), 4366, doi:10.1029/2001JD002044.

Jacobson, M. Z. (2006), Effects of externally-through-internally-mixed soot inclusions within clouds and precipitation on global climate, J. Phys. Chem. A, 110(21), 6860-6873, doi:10.1021/jp056391r.

Koch, D. (2001), Transport and direct radiative forcing of carbonaceous and sulfate aerosols in the GISS GCM, J. Geophys. Res., 106(D17), 20,311-20,332, doi:10.1029/2001JD900038.

Krudysz, M., K. Moore, M. Geller, C. Sioutas, and J. Froines (2009), Intracommunity spatial variability of particulate matter size distributions in Southern California/Los Angeles, Atmos. Chem. Phys., 9(3), 1061-1075, doi:10.5194/acp-9-1061-2009.

Lamarque, J. F., G. P. Kyle, M. Meinshausen, K. Riahi, S. J. Smith, D. P. van Vuuren, A. J. Conley, and F. Vitt (2011), Global and regional evolution of short-lived radiatively-active gases and aerosols in the Representative Concentration Pathways, Clim. Change, 109(1-2), 191-212, doi:10.1007/s10584-011-0155-0.

Malm, W. C., B. A. Schichtel, and M. L. Pitchford (2011), Uncertainties in PM2.5 gravimetric and speciation measurements and what we can learn from them, J. Air Waste Manage., 61(11), 1131-1149, doi:10.1080/10473289.2011.603998.

Mcgraw, R. (1997), Description of aerosol dynamics by the quadrature method of moments, Aerosol Sci. Technol., 27(2), 255-265, doi:10.1080/ 02786829708965471.

Minguillón, M. C., M. Arhami, J. J. Schauer, and C. Sioutas (2008), Seasonal and spatial variations of sources of fine and quasi-ultrafine particulate matter in neighborhoods near the Los Angeles-Long Beach harbor, Atmos. Environ., 42(32), 7317-7328, doi:10.1016/j. atmosenv.2008.07.036.

Moffet, R. C., B. de Foy, L. T. Molina, M. J. Molina, and K. A. Prather (2008), Measurement of ambient aerosols in northern Mexico City by single particle mass spectrometry, Atmos. Chem. Phys., 8(16), 4499-4516.

Murphy, D. M., D. S. Thomson, and T. M. J. Mahoney (1998), In situ measurements of organics, meteoritic material, mercury, and other elements in aerosols at 5 to 19 kilometers, Science, 282(5394), 1664-1669, doi:10.1126/science.282.5394.1664.

Pratt, K. A., and K. A. Prather (2009), Real-time, single-particle volatility, size, and chemical composition measurements of aged urban aerosols, Environ. Sci. Technol., 43(21), 8276-8282, doi:10.1021/es902002t.

Pratt, K. A., L. E. Hatch, and K. A. Prather (2009), Seasonal volatility dependence of ambient particle phase amines, Environ. Sci. Technol. 43(14), 5276-5281.
Qin, X., P. V. Bhave, and K. A. Prather (2006), Comparison of two methods for obtaining quantitative mass concentrations from aerosol time-of-flight mass spectrometry measurements, Anal. Chem., 78(17), 6169-6178, doi:10.1021/ac060395q.

Qin, X., K. A. Pratt, L. G. Shields, S. M. Toner, and K. A. Prather (2012), Seasonal comparisons of single-particle chemical mixing state in Riverside, CA, Atmos. Environ., 59, 587-596, doi:10.1016/ j.atmosenv.2012.05.032.

Riemer, N., M. West, R. A. Zaveri, and R. C. Easter (2009), Simulating the evolution of soot mixing state with a particle-resolved aerosol model, J. Geophys. Res., 114, D09202, doi:10.1029/2008JD011073.

Rienecker, M. M., et al. (2011), MERRA: NASA's modern-era retrospective analysis for research and applications, J. Clim., 24(14), 3624-3648, doi:10.1175/jcli-d-11-00015.1.

Schult, I., J. Feichter, and W. F. Cooke (1997), Effect of black carbon and sulfate aerosols on the Global Radiation Budget, J. Geophys. Res., 102(D25), 30,107-30,117, doi:10.1029/97JD01863.

Schwarz, J. P., et al. (2008), Measurement of the mixing state, mass, and optical size of individual black carbon particles in urban and biomass burning emissions, Geophys. Res. Lett., 35, L13810, doi:10.1029/ 2008 GL033968.

Song, X.-H., L. Hadjiiski, P. K. Hopke, L. L. Ashbaugh, O. Carvacho, G. S. Casuccio, and S. Schlaegle (1999), Source apportionment of soil samples by the combination of two neural networks based on computer-controlled scanning electron microscopy, J. Air Waste Manage., 49(7), 773-783, doi:10.1080/10473289.1999.10463848.

Spracklen, D. V., K. S. Carslaw, M. Kulmala, V. M. Kerminen, G. W. Mann, and S. L. Sihto (2006), The contribution of boundary layer nucleation events to total particle concentrations on regional and global scales, Atmos. Chem. Phys., 6, 5631-5648.

Tegen, I., and R. Miller (1998), A general circulation model study on the interannual variability of soil dust aerosol, J. Geophys. Res., 103(D20), 25,975-25,995, doi:10.1029/98JD02345.

Whitby, E. R., and P. H. McMurry (1997), Modal aerosol dynamics modeling, Aerosol Sci. Technol., 27(6), 673-688, doi:10.1080/02786829708965504.

Whiteaker, J. R., D. T. Suess, and K. A. Prather (2002), Effects of meteorological conditions on aerosol composition and mixing state in Bakersfield, CA, Environ. Sci. Technol., 36(11), 2345-2353, doi:10.1021/es011381z

Zaveri, R. A., et al. (2012), Overview of the 2010 Carbonaceous Aerosols and Radiative Effects Study (CARES), Atmos. Chem. Phys., 12(16), 7647-7687, doi:10.5194/acp-12-7647-2012.

Zelenyuk, A., J. Yang, E. Choi, and D. Imre (2009), SPLAT II: An aircraft compatible, ultra-sensitive, high precision instrument for in-situ characterization of the size and composition of fine and ultrafine particles, Aerosol Sci. Technol., 43(5), 411-424, doi:10.1080/02786820802709243. 